\title{
Association Between Levels of Serum Insulin-like Growth Factor I and Functional Recovery, Mortality, and Recurrent Stroke at a 7-year Follow-up
}

(우요 $\odot$

\section{Authors}

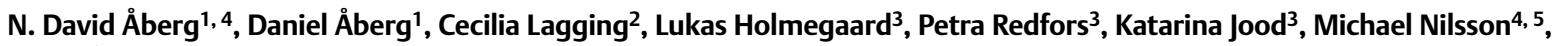
Maria Åberg6 ${ }^{6}$, Christian Blomstrand³ , Johan Svensson' ${ }^{1}$, Christina Jern², 3, Jörgen Isgaard1

\section{Affiliations}

1 Department of Internal Medicine, Institute of Medicine, The Sahlgrenska Academy at University of Gothenburg, Gothenburg, Sweden

2 Department of Clinical Pathology and Genetics, Institute of Biomedicine, The Sahlgrenska Academy at University of Gothenburg, Gothenburg, Sweden

3 Department of Clinical Neuroscience, Institute of Neuroscience and Physiology, The Sahlgrenska Academy at University of Gothenburg, Gothenburg, Sweden

4 Center of Brain Repair and Rehabilitation, The Institute of Neuroscience and Physiology, The Sahlgrenska Academy at University of Gothenburg, Gothenburg, Sweden

5 Hunter Medical Research Institute, University of Newcastle, Newcastle, Australia

6 Department of Primary Health Care, Institute of Medicine, The Sahlgrenska Academy, University of Gothenburg, Gothenburg, Sweden

Key words

cerebrovascular disease, insulin-like growth factor I, ischemic stroke, outcome, modified Rankin scale, NIHSS

$\begin{array}{ll}\text { received } & 26.10 .2018 \\ \text { revised } & 08.01 .2019 \\ \text { accepted } & 14.01 .2019\end{array}$

\section{Bibliography}

DOI https://doi.org/10.1055/a-0833-8313

Published online: 1.7.2019

Exp Clin Endocrinol Diabetes 2020; 128: 303-310

(C) J. A. Barth Verlag in Georg Thieme Verlag KG Stuttgart . New York

ISSN 0947-7349

\section{Correspondence}

Dr. N. David Åberg

Department of Internal Medicine,

Sahlgrenska University Hospital, University of Gothenburg

Gröna Stråket 8, SE-413 45 Göteborg

Sweden

Tel.: + 46/31/3428 422, Fax: +46/31/82 5330

david.aberg@medic.gu.se
(4) Supplementary Material for this article is available online at https://doi.org/10.1055/a-0833-8313

\section{ABSTRACT}

Background The association of serum insulin-like growth factor I (s-IGF-I) with favorable outcome after ischemic stroke (IS) beyond 2 years is unknown. We investigated whether the levels of s-IGF-I 3 months post-stroke were associated with functional recovery up to 7 years after IS, considering also mortality and recurrent strokes.

Methods Patients ( $\mathrm{N}=324 ; 65 \%$ males; mean age, 55 years) with s-IGF-I levels assessed 3 months after the index IS were included from the Sahlgrenska Academy Study on Ischemic Stroke (SAHLSIS). The modified Rankin Scale (mRS) was used to evaluate outcomes at 3 months, 2 and 7 years after IS, and recovery was defined as an improvement, no change, or deterioration in the shifts of mRS score. Baseline stroke severity was determined using the National Institutes of Health Stroke Scale (NIHSS).

Results The mRS score distributions were better in the abovemedian s-IGF-I group (>146.7 ng/ml). The s-IGF-I level was not associated with recurrent stroke $(N=79)$ or death $(N=44)$, although it correlated with recovery $(r=0.12, P=0.035)$. In the regression analysis, s-IGF-I associated with recovery between 3 months and 7 years (but not between 2 and 7 years). The associations did not withstand adjustment for age and sex. For comparison, the corresponding associations between 3 months and 2 years withstood all adjustments.

Conclusion The association for s-IGF-I with long-term poststroke recovery persists after 7 years, which is also reflected in the mRS score distributions at all time-points. The effects are however modest, and not driven by mortality or recurrent stroke. 


\section{Introduction}

Insulin-like growth factor I (IGF-I) affects neuronal plasticity after brain injury (for a review, see [1]). Circulating serum IGF-I (s-IGF-I) is regulated by growth hormone $(\mathrm{GH})$ from the pituitary, as well as by other factors, such as age, metabolic state, and physical activity [2,3]. Specifically, s-IGF-I is lower in elderly subjects, in those with metabolic syndrome or malnutrition, whereas a high level of physical activity is associated with a higher level of s-IGF-I. With regard to clinical outcomes after ischemic stroke (IS), higher levels of circulating s-IGF-I have been variously associated with better outcomes $2-6$ months after IS [4, 5], with worse 3-month outcomes [6], and with neutral outcomes after 1 year [7]. Furthermore, the 3-month s-IGFI levels have been reported as being independently associated with individual improvements (i.e., changes in modified Rankin scale scores; $\triangle \mathrm{mRS}$ ) in outcome [8] after IS. Furthermore, lower levels of s-IGF-I represent a risk factor for the incidence of IS, mainly first-ever IS [9], whereas an association with the incidence of recurrent IS has not been reported to our knowledge. However, post-stroke mortality has been reported to be increased in elderly patients with low levels of s-IGF-I [5]. A drawback linked to the latter 2 studies is that no adjustments were made for the effect of age on s-IGF-I level, which means that the associations are uncertain. Thus, the situation with regard to s-IGF-I and recurrent stroke and poststroke mortality has not been thoroughly investigated, and it is important to elucidate the effects of these factors on recovery per se. Specifically, in our previous study, we showed an independent association between high 3-month levels of s-IGF-I and long-term improvement in functional outcome, as assessed by crude changes in the scores on the modified Rankin scale (mRS) from 3 months to 2 years after IS [8]. Here, we present data regarding the role of the 3-month s-IGF-I level in long-term functional outcomes and recovery over an extended period of 2-7 years post-stroke, taking into account the possible effects of recurrent stroke and mortality. Thus, we investigate the associations between functional outcome and s-IGF-I with 2 different outcome definitions: 1) functional independence (defined as $\mathrm{mRS}$ score of $0-2$ ); and 2) recovery, which is defined as the direction of shifts in the mRS scores over time (mRS shift category), categorized into deterioration, no change or improvement. As we did not previously include an analysis of recurrent strokes, deaths, and mRS shift categories, the present investigation can be regarded as more comprehensive with respect to factors that are important for long-term recovery and prognosis. Thus, we also perform a re-analysis of the previous data to include these factors for the time period of 3 months to 2 years post-stroke.

We hypothesized that the s-IGF-I levels at 3 months post-stroke would be associated with a beneficial change in functional outcome (mRS shift), with or without the inclusion of recurrent stroke incidence and mortality over the 7-year follow-up.

\section{Materials and Methods}

\section{Subjects and methods}

The design of SAHLSIS has been reported elsewhere $[8,10]$. Briefly, patients ( $<70$ years of age) with first-ever or recurrent acute IS were recruited consecutively at 4 Stroke Units in western Sweden between 1998 and 2003 ( $N=600)$, and investigated for functional outcome according to the modified Rankin Scale (mRS) at 3 months, 2 and 7 years post-stroke $[11,12]$. In 407 of these subjects, the levels of s-IGFI were measured acutely or 3 months after the index stroke and investigated in relation to the mRS scores at 3 months and 2 years poststroke [8]. Thus, in the group of 407 patients, there were 373 patients with complete data for the 3-month s-IGF-I (91.6\%) (Supplemental Fig. 1S), in accordance with Strengthening the Reporting of Observational Studies in Epidemiology (STROBE) [13]. As the purpose of the present study was to study the outcomes for the patients after 7 years, we included only those patients who had completed the follow-up for 7 years and for whom the 3-month s-IGF-I levels were available. Therefore, of the original patients with 3-month s-IGF-I levels available, 324 could be followed for 7 years, thereby generating the study population in this report ( $\triangleright$ Table 1 ). Initial stroke severity was assessed based on scores in the Scandinavian Stroke Scale (SSS), which were recalculated into the now more commonly used National Institutes of Health Stroke Scale (NIHSS). Owing to skewness, the NIHSS scores were further transformed into quintiles of stroke severity, defined as follows: quintile (q)1, 0-0.74 (mild); q2, 0.74-2.03 (minor); q3, 2.03-3.75 (moderate); q4, 3.75-10.2 (major); and q5, 10.2-42 (severe). The algorithm used was: NIHSS $=25.68-0.43 \times$ SSS [14]. Crude $\mathrm{mRS}$ data were used, as well as the mRS shifts for the time periods of 3 months -7 years and 2-7 years (and for comparison, 3 months -2 years), as modified from the system of Lai and coworkers [15]. For each time period, the mRS shifts were categorized as deteriorated, unchanged or improved. The s-IGF-I levels of the study participants were analyzed in 2008 in one series of experiments. For the purpose of deriving the mRS score distributions, s-IGF-I was dichotomized as being above or below the median level of s-IGF-I ( $146.7 \mathrm{ng} /$ $\mathrm{ml}$; [8]). This cut-off median was based on the 3-month s-IGF-I in the study population of the previous study [8], but was identical to the present 3-month selection of patients with 7 years of follow-up. The 3-month s-IGF-I mean values $(152 \mathrm{ng} / \mathrm{ml})$ were lower than the acute s-IGF-I $(171 \mathrm{ng} / \mathrm{ml}, \mathrm{p}<0.01)$. However, the 3 -month s-IGF-I was very close to a smaller group of healthy sex-and age matched controls $(145 \mathrm{mg} / \mathrm{ml}, \mathrm{p}=0.44)$. Hypertension, diabetes mellitus, and smoking were defined as described previously $[8,10,16]$, and measurements of serum low-density lipoprotein (LDL) were performed at baseline. Recurrent strokes and deaths were recorded throughout the period, as described elsewhere [12]. The data and characteristics of this subsample resemble the characteristics described in previous reports based on the SAHLSIS cohort $[8,10,16]$, which together with details of the study design and clinical examination can be found in the Supplementary Information. This study was conducted in accordance with the 1964 Helsinki Declaration and subsequent amendments or comparable ethical standards. Participants or next-of-kin provided written informed consent. This study was approved by the Ethics Committee of the University of Gothenburg.

\section{Statistical analysis}

Statistical evaluations of the data were performed using the SPSS ver. 21.0 software (SPSS Inc., Chicago, IL). Crude correlations were analyzed by the method of Pearson. Furthermore, the mean s-IGF-I values are presented with respect to the mRS shift categories, crudely evaluated using $\mathrm{t}$-tests with respect to improvement vs. deterioration. In the cases with statistically significant differences, further evaluation was made using a stepwise multiple regression with respect to the $\mathrm{mRS}$ shift categories (deterioration, no change 
- Table 1 Baseline data for the included patients with s-IGF-I levels available at 3 months and those who were followed for 7 years.

\begin{tabular}{|c|c|c|c|}
\hline & & \multicolumn{2}{|l|}{3 months - 7 years } \\
\hline & & All including dead and recurr. stroke & Excluding dead and recurr. stroke \\
\hline $\mathrm{n}$ & & 324 & 245 \\
\hline \multirow[t]{2}{*}{ Sex } & Male / female $(\mathrm{N})$ & $211 / 113$ & $157 / 88$ \\
\hline & Male / female (fraction) & 0.65 & 0.64 \\
\hline Age (index) & Years (SD) & $55.3(11)$ & $54.5(11)$ \\
\hline \multirow[t]{2}{*}{ Body Mass Index (BMI) } & Mean (SD) & $26.3(4.3)$ & $26.3(4.2)$ \\
\hline & Missing (N) & 2 & 2 \\
\hline \multirow[t]{2}{*}{ Diabetes } & Yes (N / fraction) & $61(0.19)$ & $40(0.16)$ \\
\hline & Missing (N) & 0 & 0 \\
\hline \multirow[t]{2}{*}{ Hypertension } & Yes (N / fraction) & $179(0.55)$ & $130(0.53)$ \\
\hline & Missing (N) & 0 & 0 \\
\hline \multirow[t]{2}{*}{ Current smoking } & Yes (N / fraction) & $117(0.36)$ & $83(0.34)$ \\
\hline & Missing (N) & 0 & 0 \\
\hline \multirow[t]{2}{*}{ LDL level (mmol/L) } & Mean (SD) & $3.3(1.0)$ & $3.4(1.0)$ \\
\hline & Missing (N) & 27 & 22 \\
\hline \multirow[t]{2}{*}{ Stroke severity (NIHSS) } & Mean $(20 \%, 80 \%)$ & $5.1(0.74,8.5)$ & $4.85(0.74,7.6)$ \\
\hline & Missing (N) & 0 & 0 \\
\hline \multirow[t]{2}{*}{ Stroke outcome (mRS) $3 \mathrm{~m}$} & Mean (SD) & $1.83(1.03)$ & $1.76(1.01)$ \\
\hline & Missing (N) & 6 & 3 \\
\hline \multirow[t]{2}{*}{ Stroke outcome (mRS) $2 \mathrm{yr}$} & $\mathrm{mRS}(\mathrm{SD})$ & $1.81(1.33)$ & $1.60(1.09)$ \\
\hline & Missing (N) & 1 & 0 \\
\hline \multirow[t]{2}{*}{ Stroke outcome (mRS) 7yr } & $\mathrm{mRS}(\mathrm{SD})$ & $2.38(1.84)$ & $1.69(1.18)$ \\
\hline & Missing (N) & 0 & 0 \\
\hline \multirow[t]{2}{*}{ Recurrent stroke $(0-3 \mathrm{~m})$} & Yes (N / fraction) & $12(0.038)$ & $0(0)$ \\
\hline & Missing (N) & 0 & 0 \\
\hline \multirow[t]{2}{*}{ Recurrent stroke (3m-7yr) } & Yes (N / fraction) & $19(0.059)$ & $0(0)$ \\
\hline & Missing (N) & 0 & 0 \\
\hline \multirow[t]{2}{*}{ Recurrent stroke (2-7yr) } & Yes (N / fraction) & $48(0.15)$ & $0(0)$ \\
\hline & Missing (N) & 0 & 0 \\
\hline \multirow[t]{2}{*}{ Dead (3m-2yr) } & Yes (N / fraction) & $9(0.028)$ & $0(0)$ \\
\hline & Missing (N) & 0 & 0 \\
\hline \multirow[t]{2}{*}{ Dead (2-7yr) } & Yes (N / fraction) & $35(0.11)$ & $0(0)$ \\
\hline & Missing (N) & 0 & 0 \\
\hline \multirow[t]{2}{*}{ s-IGF-I (3 m, ng/mL) } & Mean (SD) & $150.7(53)$ & $151.0(52.2)$ \\
\hline & Missing (N) & 0 & 0 \\
\hline
\end{tabular}

or improvement). As in our previous publication [8], concentrations of s-IGF-I below and above the median level of s-IGF-I were used to compare the distributions of the mRS scores across time. For this purpose, the non-parametric Friedman rank test for repeated related (paired) data was used, together with a post-hoc pairwise comparison. The cardiovascular risk factors of smoking, hypertension, diabetes, and LDL levels, in addition to initial stroke severity were considered to be potential confounding factors and were entered into the multivariate analyses. Cox proportional hazards regression models were used to assess the associations between levels above and below the median s-IGF-I and: 1) recurrent stroke; and 2) death [presented as hazard ratios (HR), $95 \%$ confidence intervals $(\mathrm{Cl})$, and P-values]. A 2-tailed P-value $<0.05$ was considered statistically significant. For further details of the study design, patient examinations, protein measurements, and statistical analyses, see the Supplementary Information.

\section{Results}

\section{Baseline data}

The baseline characteristics of the study cohort with 7 years of follow-up are summarized in > Table 1. 44 patients died (14\%) and 79 suffered a recurrent stroke ( $24 \%$ ) during the 7 -year follow-up. The present baseline data can be compared to the selection with 2 years of follow-up [8] in (Supplementary Table 1S). 
Relationships between the levels of serum IGF-I at 3 months post-stroke and the outcomes at the 7-year follow-up

The distribution of the mRS scores at the 7-year follow-up for patients who had s-IGF-I concentrations above or below the median level at 3 months post-stroke is shown in $>$ Fig. 1. In the above-median s-IGF-I group, there was a net improvement in the mRS score distribution between 3 months and 7 years, and this was not present in the below-median s-IGF-I group ( $\triangleright$ Fig. 1, a and b). There were also distinct differences in the mRS score distribution between the above-median and below-median s-IGF-I levels in the group that included all the patients, as well as in the group without recurrent stroke or death ( $\vee$ Fig. 1, a,b vs. c,d).

There were no significant differences in s-IGF-I levels between the patients who subsequently died or were afflicted with a recurrent stroke between 3 months and 2 years or between 2 and 7 years ( Table 2). Although the levels of s-IGF-I were slightly higher in the subjects with mRS $0-2$ than in those with mRS 3-5 or mRS 3-6 (both time-points), the difference was not statistically significant. Furthermore, neither in the unadjusted or in the age- and sex-adjusted Cox proportional hazards regression models were there any significant associations between the above-median s-IGF-I and recurrent stroke (unadjusted $H R=1.11,95 \% \mathrm{Cl} 0.69-1.19, \mathrm{P}=0.67$; sex- and age-adjusted $\mathrm{HR}=1.23,95 \% \mathrm{Cl} 0.76-2.0, \mathrm{P}=0.4)$ or between the above-median s-IGF-I and death (unadjusted $\mathrm{HR}=0.93$, $95 \% \mathrm{Cl} 0.51-1.68, \mathrm{P}=0.8$; sex- and age-adjusted $\mathrm{HR}=1.01,95 \% \mathrm{Cl}$ $0.55-1.84, \mathrm{P}=0.97)$. Further adjustments of the cardiovascular covariates and initial stroke severity did not change the significance levels ( $P>0.3$ for all models, data not shown).

Next, we analyzed the s-IGF-I levels in relation to intra-individual shifts in the mRS scores of the patient group without recurrent stroke or deaths. In > Table 3, crude correlations between the s-IGF-I levels and mRS shift category (top), as well as the mean s-IGF-I level for each of the subsequent mRS shift categories are presented (bottom). Indeed, the s-IGF-I levels correlated with the mRS shift categories from 3 months to 7 years, although the correlation was relatively modest $(r=0.12)$. While the correlation coefficient was retained $(r=0.121)$, the significance level was reduced to a tendency when deaths and recurrent stroke were excluded. It is noteworthy that the correlation persisted from 3 months to 7 years (left column, > Table 3), whereas all of the positive correlation was derived from the period of 3 months to 2 years (right column). In terms of s-IGF-I levels, the data show a tendency $(P=0.057)$ towards significantly lower s-IGF-I levels in the group of patients who experienced deterioration until 7 years, although there is no significant difference in s-IGF-I levels between the different mRS shift categories of the subjects between 2 and 7 years post-stroke. As for the crude correlations, the s-IGF-I levels for different $m$ RS shift categories taking place between 3 months and 2 years post-stroke revealed a more marked difference between deterioration and improvement.

\section{The relationship between the s-IGF-I levels at 3 months post-stroke and the timing of recovery}

To assess the potential associations, we used multiple stepwise regression models. We expected to discover associations in line with the previously reported independent association between the crude mRS improvements until 2 years post-stroke and measured levels of
s-IGF-I [8]. Thus, after exclusion of cases of death and recurrent strokes, the association between the 3-month s-IGF-I levels and mRS shift categories between 3 months and 2 years withstood adjustments for sex, age, and cardiovascular confounders (partial $r=0.146$, $P=0.01$ ), and additionally for initial stroke severity (partial $r=0.142$, $P=0.036$ ). With regard to the associations between the 3 -month sIGF-I levels and the mRS shifts from 3 months until 7 years, age turned out to be a more important factor (partial $r=-0.223$, $P<0.001$ ), reducing the partial correlation of 3-month s-IGF-I levels with mRS shift categories from 3 months until 7 years post-stroke to non-significant levels (partial $r=0.064, P=0.33$ ). No further adjustments were made with regard to the mRS shift in the 7-year followup. Taken together, this indicates that the 3-month s-IGF-I level is associated with recovery ( $m R S$ shift categories) between 3 months and 2 years post-stroke, and that no further significant association with mRS shifts are found between 2 years and 7 years post-stroke.

\section{Discussion and Conclusions}

\section{Post-stroke 3-month serum-IGF-I levels are associated with the 7-year mRS shifts, although most of these shifts take place prior to 2 years post-stroke}

This is a 7-year follow-up of a previous study [8] that investigated the long-term effects of the levels of s-IGF-I 3 months post-stroke on the actual mRS scores and mRS shifts recorded 3 months and 2 years post-stroke. For $79.6 \%$ of those patients, we were able to examine the functional status at 7 years post-stroke. To the best of our knowledge, this is the first report showing data with such a long follow-up with regard to s-IGF-I after IS. The 3-month s-IGF-I level was neutral with respect to the 7-year mRS score, in agreement with the neutral relationship noted between the 3-month s-IGF-I level and 2-year mRS score (both crude correlations and mRS $0-2$ vs. mRS 3-5). With respect to the mRS score distributions, there were differences in the time-dependent development of mRS score distributions in the above-median and below-median s-IGF-I groups, with a more favorable projection of $\mathrm{mRS}$ score distribution in the groups without deaths and recurrent stroke ( $\triangleright$ Fig. $\mathbf{1} \mathbf{a}$ and $\mathbf{b}$ ) and in the entire cohort ( $\triangleright$ Fig. 1c and d). The beneficial association between s-IGF-I and individual mRS shift category was mostly confined to 2 years post-stroke, although the relationship was preserved at 7 years post-stroke. The association of 3-month s-IGF-I levels with changes in mRS scores until 2 years post-stroke is independent of age, whereas the association between the 3-month s-IGF-I and mRS shifts from 3 months until 7 years is primarily mediated by age (i. e., increasing age is more important than s-IGF-I level). Although some effect of s-IGF-I is preserved at 7 years post-stroke, the effect size is limited, with correlation coefficients for s-IGF-I and recovery ranging from 0.12 to $0.18-0.19$. Finally, there were no significant associations between the 3 -month sIGF-I level and recurrent strokes or deaths during the 7-year followup. Although direct comparisons cannot be made due to the different study conditions, this result is discrepant with previous reports showing a U-shaped relationship for s-IGF-I with regard to primary all-cause mortality [meta-analysis in [17]. It also contrasts with a previous report on a linkage between low s-IGF-I levels and a clearly higher incidence of IS, presumably mainly first-ever IS [9]. However, we are not 
a mRS - below median IGF-I, exclusions\#

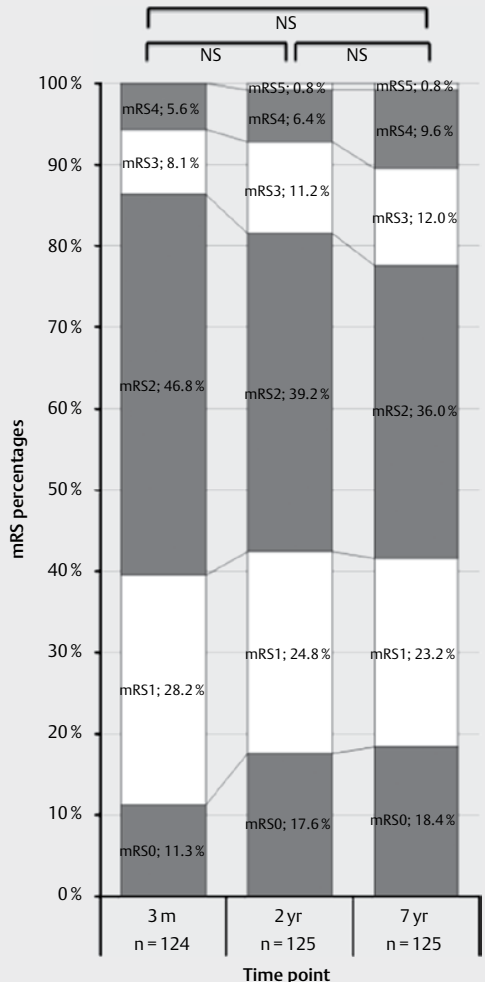

c

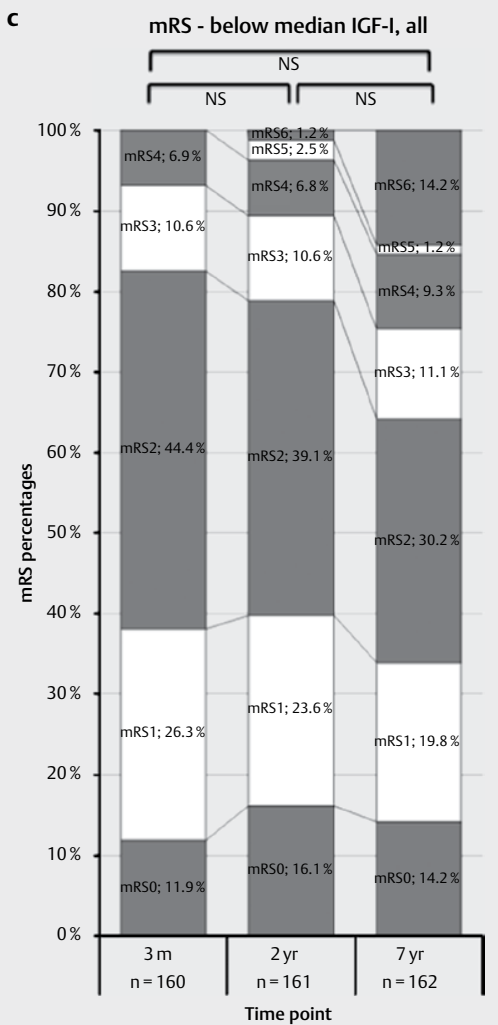

b

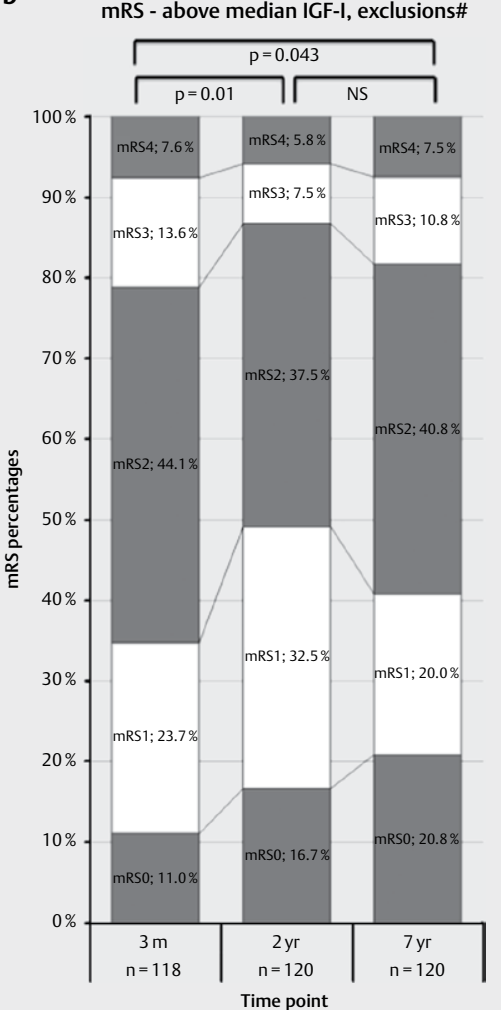

d

mRS - above median IGF-I, all

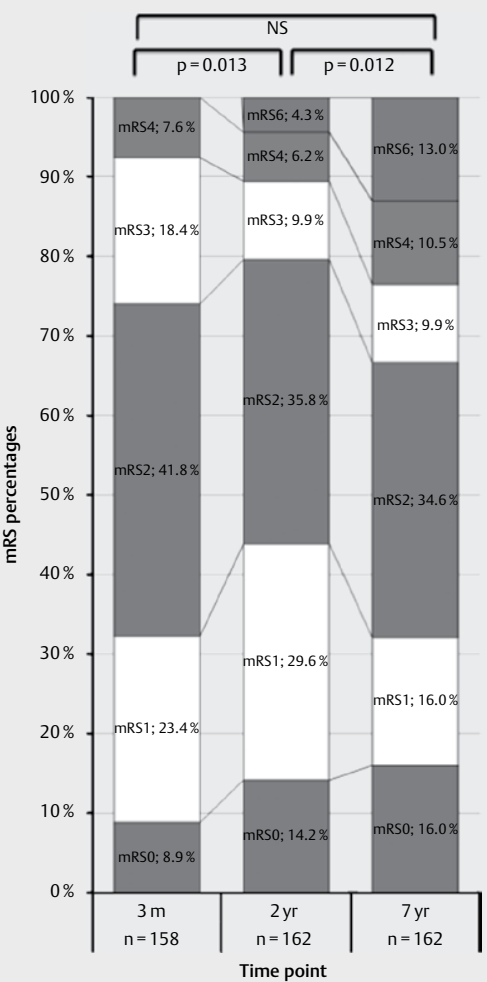

-Fig. 1 Values below or above the median serum-IGF-I concentration at 3 months post-stroke are related to changes in mRS score distributions for up to 7 years of follow-up. a-b. Distributions of mRS scores $0-5$ (at 3 months, 2 and 7 years post-stroke), excluding patients with recurrent strokes and deaths, for patients below a and above $\mathbf{b}$ the median 3-month s-IGF-I level. c-d. Distributions of mRS scores $0-6$ (at 3 months, 2 and 7 years post-stroke), including patients with recurrent stroke, for patients below the median s-IGF-I level $\mathbf{c}$ and above the median s-IGF-I level d. The nonparametric Friedman test for repeated observations was used to analyze the mRS score distributions and the post-hoc pairwise comparisons with their respective P-values are shown (see Methods section). 
- Table 2 Data for 3-month s-IGF-I with regard to overall favorable mRS (0-2) and unfavorable mRS (3-6), deaths, and recurrent stroke at 2 and 7 years after the index ischemic stroke.

\begin{tabular}{|c|c|c|c|c|c|c|c|}
\hline & & \multicolumn{3}{|l|}{2 years } & \multicolumn{3}{|l|}{7 years } \\
\hline & & S-IGF-I $\left( \pm \mathrm{Cl}^{4}\right)$ & $\mathbf{N}$ & $\mathbf{P}^{3}$ & S-IGF-I $\left( \pm \mathrm{Cl}^{4}\right)$ & $\mathbf{N}$ & $\mathbf{P}^{3}$ \\
\hline \multirow[t]{7}{*}{ All patients ${ }^{1}$} & mRS 0-2 & $151.5(6.6)$ & 256 & $>0.3$ & $153.0(16.6)$ & 212 & $>0.3$ \\
\hline & mRS 3-6 & $148.3(12.3)$ & 67 & & $145.6(7.0)$ & 111 & \\
\hline & Missing mRS & & 1 & & & 0 & \\
\hline & Death (3-24 months) & \multicolumn{2}{|l|}{ See next column } & & $165.4(34.7)$ & 9 & 0.275 \\
\hline & Death (24-84 months) & \multicolumn{2}{|l|}{ See next column } & & $142.5(18.5)$ & 35 & \\
\hline & $\begin{array}{l}\text { Recurrent stroke (3-24 } \\
\text { months) }\end{array}$ & \multicolumn{2}{|l|}{ See next column } & & $162.3(26.3)$ & 19 & 0.135 \\
\hline & $\begin{array}{l}\text { Recurrent stroke (24-84 } \\
\text { months) }\end{array}$ & \multicolumn{2}{|l|}{ See next column } & & $139.3(15.6)$ & 48 & \\
\hline Selected & mRS $0-2$ & $152.9(7.2)$ & 206 & $>0.3$ & $152.8(7.2)$ & 195 & $>0.3$ \\
\hline patients ${ }^{2}$ & mRS 3-5 & $140.9(15.1)$ & 39 & & $143.9(15.6)$ & 50 & \\
\hline
\end{tabular}

${ }^{1}$ The s-IGF-I values are shown with no exclusions, for all patients; ${ }^{2}$ The s-IGF-I values are shown with exclusion of deaths and recurrent strokes during the time period; ${ }^{3 \mathrm{P}}$-values obtained using the Student's t-test; ${ }^{4} \mathrm{Cl}, 95 \%$ confidence interval.

aware of any previous report showing specifically the relationship between the incidence of recurrent IS and s-IGF-I. Moreover, post-stroke mortality has been reported to be increased in patients with low levels of s-IGF-I [5]. Since in the last 2 studies no adjustments were made for the effect of age on s-IGF-I [5,9], the reported associations may be more uncertain than our data obtained from the Cox proportional hazards regression models with adjustments for sex and age. This is supported by the difference in HRs noted between the unadjusted models and sex- and age-adjusted models, which suggests that adjustment for age is very important when assessing the effects of sIGF-I and when carrying out comparisons with previous studies.

\section{Methodological aspects}

The reliability of the results of the present study is strengthened by the consecutive recruitment of well-characterized and relatively young IS patients and the high hospitalization rate (84\%-95\%) for stroke patients (especially those aged $<70$ years) in Sweden [18]. As compared to our study of 2011, there are some differences of inclusion [8]. The reasons for not including the acute levels of s-IGF-I in the present study are that there was no significant association with the crude mRS score (at either 3 months or 2 years) and that the association for acute s-IGF-I with mRS score changes $(\Delta \mathrm{mRS})$ was substantially weaker than that for the 3-month s-IGF-I and $\Delta \mathrm{mRS}$ [8]. Furthermore, as the initial change in s-IGF-I level was associated primarily with the 3-month mRS score and less so with the long-term 2-year mRS score [19], we did not analyze this parameter in this longterm follow-up. Although some patients were lost to follow-up between the 2 years and 7 years, we consider the selection bias to be minimal for the parameters included in the study ( $\triangleright$ Table 1 , and for comparison, see Supplementary Table 1S). There may, however, be a bias associated with the somewhat higher retrieval of patients who died (generating mRS score of 6), as such data can be retrieved from cause of death registers rather than through informed-consent active follow-up with clinical examination or interview. The longitudinal design with 3 time-points for the assessment of mRS scores allowed us to sort the patients into 3 categories of mRS shifts (deterioration, no change and improvement), for the respective time pe- riods, in a modification to the previous regression analysis of shifts in crude $\Delta \mathrm{mRS}$ scores [15]. Although the frequencies of deaths and recurrent stroke were low up to 2 years post-stroke, the overall consideration of these events over the entire study 7-year follow-up makes the present report more scientifically robust. Therefore, it can be stated that the 3-month s-IGF-I levels have no major associations with recurrent stroke or mortality, although there is an association with recovery evaluated using the mRS shifts, independent of recurrent stroke and mortality. The weaknesses of the present study are the relatively small sample size and the lack of replication in a different geographic area. Although the relatively young age of the patients (mean, 55 years) makes it possible to follow patients for long periods (partly due to the low death rates), it also restricts the generalizability to older stroke populations. The relatively young age of the subjects also disfavors the recurrence of stroke and occurrence of mortality.

\section{Possible significance of mRS shifts and serum IGF-I levels}

In the literature, high levels of s-IGF-I are generally considered as beneficial with respect to cognitive functions and neuroprotection after acute stroke (for a review, see [1]). Although animal experiments with IGF-I treatments have shown robust neuroprotective effects, it is important to bear in mind that endogenous s-IGF-I may play a different role in functional outcome after stroke. As local levels of IGF-I in the central nervous system have been reported to increase after experimental IS [20], it will be important to confirm this by determining the cerebrospinal fluid (CSF) concentrations of IGF-I. At 3 months poststroke, however, the s-IGF-I levels in patients with IS are decreased to close to the levels found in healthy controls [8]. Therefore, the present investigation focused on this more stabilized level of s-IGF-I. It may be of importance that s-IGF-I appears to be dynamically regulated in the post-stroke period [19,21], and this may explain why there are different associations with functional outcomes in different studies [4-8], depending on which post-stroke time-point was used for s-IGF-I sampling. Nevertheless, a stabilized 3-month level of s-IGF$\mathrm{I}$ is independently associated with recovery ( $\mathrm{mRS}$ shift categories) be- 
- Table 3 Data for the 3-month s-IGF-I levels and shifts in mRS scores for patients who were followed for 7 years (cases of recurrent strokes and death are excluded).

\begin{tabular}{|c|c|c|c|c|c|c|c|c|c|c|}
\hline \multirow{3}{*}{ Selection ${ }^{1}$} & \multirow{3}{*}{ Analysis } & \multicolumn{3}{|c|}{ mRS shifts over ${ }^{6}$} & & & \multirow[b]{3}{*}{$\mathrm{P}^{4}$} & & & \multirow[b]{3}{*}{$\mathrm{P}^{4}$} \\
\hline & & \multicolumn{2}{|c|}{3 months -7 years } & & \multicolumn{2}{|l|}{$2-7$ years } & & \multicolumn{2}{|c|}{3 months - 2 years } & \\
\hline & & $r$ & $\mathrm{~N}$ & $\mathrm{P}^{4}$ & $r$ & $\mathrm{~N}$ & & $r$ & $\mathrm{~N}$ & \\
\hline \multicolumn{11}{|l|}{ All data } \\
\hline & correlation & 0.120 & 318 & 0.035 & -0.01 & 323 & $>0.3$ & 0.183 & 317 & 0.001 \\
\hline & missing & & 6 & & & 1 & & & 7 & \\
\hline \multicolumn{11}{|c|}{ Alive, no recurrent stroke } \\
\hline & correlation & 0.121 & 242 & 0.061 & -0.052 & 245 & $>0.3$ & 0.19 & 242 & 0.003 \\
\hline & missing & & 3 & & & 0 & & & 3 & \\
\hline & & \multicolumn{2}{|c|}{ mRS shifts over ${ }^{6}$} & & & & & & & \\
\hline & & \multicolumn{2}{|c|}{3 months - 7 years } & & \multicolumn{2}{|l|}{$2-7$ years } & & \multicolumn{2}{|c|}{3 months - 2 years } & \\
\hline & & s-IGF-I $\left( \pm \mathrm{Cl}^{7}\right)$ & & & s-IGF-I $\left( \pm \mathrm{Cl}^{7}\right)$ & & & s-IGF-I $\left( \pm \mathrm{Cl}^{7}\right)$ & & \\
\hline Selection $^{2}$ & Category & $\begin{array}{l}\text { by mRS } 3 \\
\text { months }\end{array}$ & $\mathrm{N}$ & $\mathrm{P}^{5}$ & $\begin{array}{l}\text { by } \mathrm{mRS} 2 \\
\text { years }\end{array}$ & $\mathrm{N}$ & $\mathrm{P}^{5}$ & $\begin{array}{l}\text { by mRS } 3 \\
\text { months }\end{array}$ & $\mathrm{N}$ & $\mathrm{P}^{5}$ \\
\hline \multicolumn{3}{|c|}{ Pooled mRS 0-5 (no recurrent stroke) } & 242 & & & 245 & & & 242 & \\
\hline & deterioration & $136.4(12.3)$ & 44 & 0.057 & $154.6(14.7)$ & 53 & $>0.3$ & $126.8(14.4)$ & 30 & 0.005 \\
\hline & no shift & $152.8(8.7)$ & 123 & & $151.3(8.1)$ & 148 & & $150.6(8.0)$ & 142 & \\
\hline & improvement & $156.5(13.9)$ & 75 & & $145.8(16.9)$ & 44 & & $162.0(14.4)$ & 73 & \\
\hline \multicolumn{3}{|c|}{ Missing regarding mRS change } & 3 & & & 0 & & & 3 & \\
\hline \multicolumn{11}{|c|}{ By each initial mRS } \\
\hline \multirow[t]{2}{*}{ mRS 0} & deterioration & $130.9(23.0)$ & 4 & $>0.3$ & $146.0(19.8)$ & 13 & $>0.3$ & $148.5(37.4)$ & 8 & $>0.3$ \\
\hline & no shift & $151.8(19.9)$ & 23 & & $145.2(17.3)$ & 29 & & $148.8(19.8)$ & 19 & \\
\hline \multirow[t]{3}{*}{ mRS 1} & deterioration & $140.2(16.6)$ & 25 & $>0.3$ & $155.6(20.2)$ & 24 & $>0.3$ & $125.9(19.8)$ & 13 & 0.28 \\
\hline & no shift & $147.3(19.2)$ & 20 & & $158.4(21.3)$ & 31 & & $149.3(16.9)$ & 33 & \\
\hline & improvement & $138.9(22.6)$ & 18 & & $151.2(29.2)$ & 15 & & $140.5(17.5)$ & 17 & \\
\hline \multirow[t]{3}{*}{$\mathrm{mRS} 2$} & deterioration & $126.5(26.6)$ & 12 & 0.138 & $174.3(46.7)$ & 11 & 0.207 & $105.6(17.2)$ & 7 & 0.025 \\
\hline & no shift & $152.7(11.6)$ & 61 & & $154.1(11.7)$ & 65 & & $150.6(11.6)$ & 67 & \\
\hline & improvement & $157.3(21-0)$ & 37 & & $141.6(26.5)$ & 18 & & $161.9(20.5)$ & 36 & \\
\hline \multirow[t]{3}{*}{$\mathrm{mRS} 3$} & deterioration & $151.7(47.7)$ & 3 & $>0.3$ & $128.6(40.2)$ & 5 & 0.296 & 103.8 & 1 & $>0.3$ \\
\hline & no shift & $136.8(29.0)$ & 9 & & $132.7(27.0$ & 11 & & $161.0(31.7)$ & 12 & \\
\hline & improvement & $183.3(29.9)$ & 14 & & $163.3(43.3)$ & 7 & & $170.6(29.4)$ & 13 & \\
\hline \multirow[t]{3}{*}{$\mathrm{mRS} 4$} & deterioration & $\mathrm{N} / \mathrm{A}^{3}$ & 0 & $\mathrm{~N} / \mathrm{A}^{3}$ & $\mathrm{~N} / \mathrm{A}$ & 0 & $\mathrm{~N} / \mathrm{A}^{3}$ & 137.1 & 1 & $N / A^{3}$ \\
\hline & no shift & $180.8(47.9)$ & 10 & & $149.5(22.7)$ & 12 & & $146.7(31.9)$ & 11 & \\
\hline & improvement & $141.5(57.2)$ & 6 & & $105.6(80.9)$ & 3 & & $226.4(108.0)$ & 4 & \\
\hline $\mathrm{mRS} 5$ & improvement & $\mathrm{N} / \mathrm{A}^{3}$ & 0 & $\mathrm{~N} / \mathrm{A}^{3}$ & 137.1 & 1 & $\mathrm{~N} / \mathrm{A}^{3}$ & $N / A^{3}$ & 0 & $N / A^{3}$ \\
\hline \multicolumn{11}{|c|}{$\begin{array}{l}{ }^{1} \text { Category of shifts in mRS scores, as analyzed by crude correlations (above); }{ }^{2} \text { Category of shifts in mRS scores, as analyzed by differences in the } \\
\text { absolute s-IGF-I levels (below); }{ }^{3} \mathrm{~N} / \mathrm{A} \text {, not applicable; }{ }^{4} \mathrm{P} \text {-values obtained using Pearson correlation for mRS shift categories of deterioration vs. } \\
\text { improvement or for initial mRS }=0 \text {, deterioration vs. no shift, with rho values ( } \mathrm{r} \text { ) given; }{ }^{5} \mathrm{P} \text {-values obtained using the Student's t-test (for mRS shift } \\
\text { categories of deterioration vs. improvement or for initial mRS }=0 \text {, deterioration vs. no shift); }{ }^{6} \text { Data for the mRS score shift categories between } 3 \\
\text { months and } 7 \text { years and between } 2 \text { and } 7 \text { years are shown. For comparison, the shifts in mRS scores for the period } 3 \text { months and } 2 \text { years period from } \\
3 \text { months to } 2 \text { years are shown with the same selection of patients; }{ }^{7} \mathrm{Cl}, 95 \% \text { confidence interval. }\end{array}$} \\
\hline
\end{tabular}

tween 3 months and 2 years post-stroke, while the effect is less pronounced but still significant when one compares the results at 3 months and 7 years post-stroke. The changes are also reflected in different mRS score distributions at 3 months, and at 2 years and 7 years ( $\triangleright$ Fig. 1). Taken together, these results point to a relatively modest effect of 3-month IGF-I level with respect to long-term (7-year) stroke outcome. It is known that s-IGF-I levels decrease with age, which is relatively predictable $[8,22]$. However, the level of s-IGF-I is also decreased by malnutrition, and to some degrees by physical inactivity $[2,3]$ and infectious diseases [23]. Therefore, the independent associations with recovery warrant further studies with additional time- points for blood sampling, both in the early post-stroke period with consideration of physical activity, infections, and nutritional status and in long-term follow-up after 2, 5 and 7 years. Our results also suggest that a specific s-IGF-I level is a better predictor of the mRS shifts within the ensuing 1-2 years, than in more extended time periods.

\section{Conclusions}

In summary, our study indicates that the s-IGF-I level at 3 months poststroke is neutrally related to the mRS scores at 2 and 7 years. However, there is significantly better individual recovery, as evidenced by the 
mRS shift categories, between 3 months and 7 years post-stroke, although most of the clinical benefit occurs within the 2 years after the initial stroke. No significant relationships were found between the 3-month s-IGF-I levels and recurrent stroke or deaths, and the effects on recovery were also independent of these parameters. These data provide the foundation for further studies with more sampling points, both early after stroke and also at extended follow-up time-points, and the possible inclusion of measurements of IGF-I levels in the CSF.

\section{Acknowledgments}

The authors wish to thank Dr. Vincent Collins for careful correction of the English language of the manuscript. This study was supported by the Swedish Medical Society (Svenska Läkaresällskapet), grants from the Swedish Government (ALFGBG-719761, ALFGBG-751111), the Swedish Stroke Association, the Göteborg Foundation for Neurological Research, and the Yngve Land, Rune and Ulla Amlöv, Edit Jacobson, Magnus Bergvall, Emelle, Lars Hierta, and John and Brit Wennerström Foundations.

\section{Conflict of Interest}

No conflict of interest has been declared by the authors.

\section{References}

[1] Åberg ND, Brywe KG, Isgaard J. Aspects of growth hormone and insulin-like growth factor-I related to neuroprotection, regeneration, and functional plasticity in the adult brain. Scientific World Journal 2006; 6: 53-80; doi:10.1100/tsw.2006.22

[2] Parekh N, Roberts CB, Vadiveloo M et al. Lifestyle, anthropometric, and obesity-related physiologic determinants of insulin-like growth factor- 1 in the Third National Health and Nutrition Examination Survey (1988-1994). Ann Epidemiol 2010; 20: 182-193; doi:10.1016/j. annepidem.2009.11.008

[3] Landin-Wilhelmsen K, Wilhelmsen L, Lappas G et al. Serum insulin-like growth factor $I$ in a random population sample of men and women: Relation to age, sex, smoking habits, coffee consumption and physical activity, blood pressure and concentrations of plasma lipids, fibrinogen, parathyroid hormone and osteocalcin. Clin Endocrinol (Oxf) 1994; 41: 351-357

[4] Bondanelli M, Ambrosio MR, Onofri A et al. Predictive value of circulating insulin-like growth factor I levels in ischemic stroke outcome. J Clin Endocrinol Metab 2006; 91: 3928-3934; doi:10.1210/ jc.2006- 1040

[5] Denti L, Annoni V, Cattadori E et al. Insulin-like growth factor 1 as a predictor of ischemic stroke outcome in the elderly. Am J Med 2004; 117: 312-317; doi:10.1016/j.amjmed.2004.02.049

[6] Armbrust M, Worthmann H, Dengler R et al. Circulating insulin-like growth factor- 1 and insulin-like growth factor binding protein-3 predict three-months outcome after ischemic stroke. Exp Clin Endocrinol Diabetes 2017; 125: 485-491; doi:10.1055/s-0043-103965

[7] Ebinger M, Ipsen N, Leonards CO et al. Circulating insulin-like growth factor binding protein-3 predicts one-year outcome after ischemic stroke. Exp Clin Endocrinol Diabetes 2015; 123: 461-465; doi:10.1055/s-0035-1554632
[8] Åberg D, Jood K, Blomstrand C et al. Serum IGF-I levels correlate to improvement of functional outcome after ischemic stroke. J Clin Endocrinol Metab 2011; 96: E1055-E1064; doi:10.1210/jc.2010-2802

[9] Johnsen SP, Hundborg HH, Sorensen HT et al. Insulin-like growth factor (IGF) I, - II, and IGF binding protein-3 and risk of ischemic stroke. J Clin Endocrinol Metab 2005; 90: 5937-5941 doi:10.1210/jc.2004-2088

[10] Jood K, Ladenvall C, Rosengren A et al. Family history in ischemic stroke before 70 years of age: The Sahlgrenska Academy Study on Ischemic Stroke. Stroke 2005; 36: 1383-1387; doi:10.1161/01. STR.0000169944.46025.09

[11] Redfors P, Hofgren C, Eriksson I et al. The Barrow Neurological Institute screen for higher cerebral functions in cognitive screening after stroke. J Stroke Cerebrovasc Dis 2014; 23: 349-355; doi:10.1016/j.jstrokecerebrovasdis.2013.04.026

[12] Redfors P, Isaksen D, Lappas $G$ et al. Living alone predicts mortality in patients with ischemic stroke before 70 years of age: A long-term prospective follow-up study. BMC Neurol 2016; 16: 80; doi:10.1186/ s12883-016-0599-y

[13] Vandenbroucke JP, von Elm E, Altman DG et al. Strengthening the Reporting of Observational Studies in Epidemiology (STROBE): Explanation and elaboration. PLoS Med 2007; 4: e297; doi:10.1371/ journal.pmed.0040297

[14] Gray L], Ali M, Lyden PD et al. Virtual International Stroke Trials Archive Collaboration. J Stroke Cerebrovasc Dis. 2009; 18: 466-468. doi:10.1016/j.jstrokecerebrovasdis.2009.02.003

[15] Lai SM, Duncan PW. Stroke recovery profile and the Modified Rankin assessment. Neuroepidemiology 2001; 20: 26-30; doi: $10.1159 / 000054754$

[16] Olsson S, Jood K, Blomstrand C et al. Genetic variation on chromosome 9 p21 shows association with the ischaemic stroke subtype largevessel disease in a Swedish sample aged < $1=70$. Eur J Neurol 2011; 18: 365-367; doi:10.1111/j.1468-1331.2010.03096.x

[17] Burgers AM, Biermasz NR, Schoones JW et al. Meta-analysis and dose-response metaregression: circulating insulin-like growth factor I (IGF-I) and mortality. J Clin Endocrinol Metab 2011; 96: 2912-2920; doi:10.1210/jc.2011-1377

[18] Hallström B, Jonsson AC, Nerbrand C et al. Lund Stroke Register: Hospitalization pattern and yield of different screening methods for first-ever stroke. Acta Neurol Scand 2007; 115: 49-54; doi:10.1111/j.1600-0404.2006.00738.x

[19] Åberg ND, Åberg D, Jood K et al. The change in circulating insulin-like growth factor I (IGF-I) after ischemic stroke is independently associated with outcome. In, European Stroke Organisation Conference. Gothenburg: European Stroke Journal; 2018: 342-343 (AS316-018)

[20] Beilharz E], Russo VC, Butler G et al. Co-ordinated and cellular specific induction of the components of the IGF/IGFBP axis in the rat brain following hypoxic-ischemic injury. Brain Res Mol Brain Res 1998; 59: 119-134

[21] Mattlage AE, Rippee MA, Sandt ] et al. Decrease in insulin-like growth factor- 1 and insulin-like growth factor- 1 ratio in the first week of stroke is related to positive outcomes. J Stroke Cerebrovasc Dis 2016; 25: 1800-1806; doi:10.1016/j.jstrokecerebrovasdis.2016.03.054

[22] Berrigan D, Potischman N, Dodd KW et al. Race/ethnic variation in serum levels of IGF-I and IGFBP-3 in US adults. Growth Horm IGF Res 2009; 19: 146-155; doi:10.1016/j.ghir.2008.08.005

[23] Papastathi C, Mavrommatis A, Mentzelopoulos S et al. Insulin-like growth factor $i$ and its binding protein 3 in sepsis. Growth Horm IGF Res 2013; 23: 98-104; doi:10.1016/j.ghir.2013.03.005 